\title{
An intervention for improving the lifestyle habits of kindergarten children in Israel: a cluster-randomised controlled trial investigation
}

\author{
Liat Lerner-Geva ${ }^{1,2, *}$, Elinor Bar-Zvi², Gila Levitan ${ }^{1}$, Valentina Boyko ${ }^{1}$, \\ Brian Reichman ${ }^{1,2}$ and Orit Pinhas-Hamiel ${ }^{2,3}$ \\ 'Women and Children's Health Research Unit, The Gertner Institute for Epidemiology and Health \\ Policy Research, Ltd, Tel Hashomer, Israel 52621: '2Sackler Faculty of Medicine, Tel-Aviv University, \\ Tel-Aviv, Israel: ${ }^{3}$ Pediatric Endocrinology \& Diabetes Unit, Chaim Sheba Medical Center, Tel Hashomer, \\ Israel
}

Submitted 15 July 2013: Final revision received 6 January 2014: Accepted 31 January 2014: First published online 12 March 2014

\begin{abstract}
Objective: To assess the effectiveness of an intervention programme to improve kindergarten children's eating and leisure habits in Israel.

Design: A cluster-randomised controlled trial.

Setting: Six full-day kindergartens in Israel were randomly divided into three groups. Group A received the full intervention programme, which included lessons on good eating habits and daily physical exercise. Group B received a partial intervention of lessons only. Group C, the reference group, did not receive any intervention.

Subjects: Children aged 4-6 years ( $n$ 204) were recruited for the study.

Methods: Objective data for weight and height were collected to calculate BMI $Z$-scores. Activity, sedentary time, sleeping hours and daily energy intake were assessed via a parental questionnaire. Nutritional knowledge was assessed by a single dietitian using a questionnaire addressed to the children. Assessments were done at baseline and at the end of the intervention.

Results: After adjustment for baseline levels we observed a significant reduction in daily energy intake for the full intervention group A $(P=0 \cdot 03)$. A positive intervention effect was demonstrated on nutritional knowledge in the partial intervention group B $(P=0 \cdot 03)$, although no significant change was demonstrated for BMI $Z$-score.

Conclusions: The study supports the incorporation of education on healthy lifestyle habits and physical activity into the curricula of kindergartens.
\end{abstract}

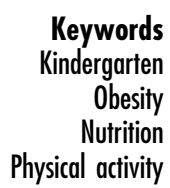

Obesity among children has become an epidemic. In 2010, the $\mathrm{WHO}^{(1)}$ reported that approximately 43 million children under the age of 5 years were overweight. In the USA the current prevalence of obesity is $16.9 \%$ in children aged 2-19 years ${ }^{(2)}$. In Israel, our previous research demonstrated that $40 \%$ of children in the kindergartens studied were either overweight $(25 \%)$ or obese $(15 \%)^{(3)}$. Similar reports in Israel are comparative to international findings ${ }^{(4)}$.

It is worthwhile to note that following the institution of intervention strategies across countries, a plateau in the rates of overweight and obesity has been reported ${ }^{(5)}$. However, obesity rates are still at an unacceptably high level. Obesity remains a public health priority that requires maintained and further intervention.

Obesity in children is a cause for concern and action due to the early onset of co-morbidities, its adverse effects on psychological well-being, the economic burden it places on society and its tendency to track into adulthood with associated risk factors ${ }^{(6-10)}$. New findings in Israel report an overweight prevalence for male and female adolescents of $23 \cdot 68 \%$ and $19 \cdot 84 \%$, respectively, and an obesity prevalence of $6 \cdot 33 \%$ and $5 \cdot 21 \%$ for males and females, respectively ${ }^{(11)}$. A report in Israel that childhood overweight and obesity are strong risk factors for adolescent overweight and obesity among Israeli youth supports strategies aimed at obesity prevention ${ }^{(12)}$.

Changes in children's lifestyle, such as the increasing consumption of sugary drinks, irregular eating patterns and increasing sedentary time in front of computers and televisions, combined with decreased amount of physical exercise are contributing factors towards creating an 'obesogenic' environment that reinforces unhealthy behaviour patterns ${ }^{(13-17)}$. 
Current recommendations are to institute interventions that address these factors based on behavioural change theory ${ }^{(18-21)}$. School-based interventions targeting various outcomes, such as good eating habits and physical activity, have demonstrated significant changes in behaviour $^{(22)}$. This has important implications for researchers and policy makers. Early-care education has also been identified as a recommended framework for conducting an intervention for young children ${ }^{(23)}$.

However, there exists a gap in research to determine effective interventions in young children ${ }^{(24)}$. There is a need for guidelines regarding physical activity to inform policy for pre-school children ${ }^{(25)}$. Nemet et al. ${ }^{(26)}$ evaluated an intervention in low socio-economic kindergarten children and showed an improvement in nutritional knowledge and preferences; however, no measurements of energy intake were carried out. The present study aimed to investigate the effectiveness of an intervention involving education on nutrition and physical activity for kindergarten children with a moderate to high socioeconomic background in the centre of Israel.

\section{Methods}

\section{Participants and setting}

The study population comprised children aged 4-6 years attending full-day kindergartens in the city of Ra'anaana. Ra'anaana is located in the centre of Israel with a population of approximately 69000 people. Ra'anaana is placed in the second highest rank of socio-economic clusters of the population ${ }^{(27,28)}$. Kindergartens considered for inclusion were those that ran a full-day programme until 16.00 hours, which all received lunch from the same catering service and had the same standard of physical exercise of $1 \mathrm{~h} /$ week.

In the city of Ra'anaana there were twenty-seven kindergartens that fulfilled these criteria. Six kindergartens were randomly approached to participate in the programme, with a total of 204 children, as described in Table 1. The kindergartens were then further randomly divided into three groups, each group comprising two kindergartens. A kindergarten was considered the unit of randomisation.

The first (group A) comprised sixty-nine children who received a full intervention programme that included both lessons on good eating habits and daily physical exercise sessions. The second (group B) comprised sixtyseven children who received an intervention programme that included only lessons on good eating habits. The third (group C) comprised sixty-eight children who did not receive any intervention and was the reference group.

Parental consent was obtained at the beginning of the programme. All parents were invited to an information evening at the beginning of the programme, where they received an explanation of the research without knowing to which group their child would be allocated. At this evening, parents were provided with an informative lecture by a dietitian about children's eating patterns. Parents were requested to complete questionnaires pertaining to their child's food consumption outside the kindergarten, at the beginning and at the completion of the programme after 4 months. Another questionnaire was distributed that requested demographic data including birthplace, years of education and family status (where the category of not married includes divorced, single parent and widowed). Religious observance was determined by parents choosing the option of the categories religious or secular.

The trial received institutional review board approval from Chaim Sheba Medical Center, Tel Hashomer, Israel (\#3576, 2005).

\section{Procedure}

Nutritional intervention

A programme for kindergarten children was created based on an existing programme 'It Fits Me' ('Tafur Alay') for primary-school children in conjunction with representatives from the Ministry of Health, the Ministry for Education, kindergarten teachers and the research team. A programme was developed consisting of ten lessons covering topics such as food groups, the importance of eating breakfast, what is calcium and why it is important, water as a healthy drink option and promoting healthy food choices such as fruits and vegetables.

For each lesson, supporting materials were developed including posters, worksheets, games, colouring-in sheets and instruction materials for teachers, and a summary for parents about each lesson was provided to reinforce the messages given over in the lessons. Teachers were given training by attending lectures where they were familiarised with the materials, in order to facilitate their ability to perform the lessons in their classes.

The programme was carried out by teachers in group A and group B. All together, four kindergartens received this intervention. One lesson was provided each week for 10 weeks.

\section{Physical activity intervention}

A daily exercise programme for kindergarten children was developed, in collaboration with a technical training college (Kibbutzim College; http://www.smkb.ac.il/), by a specialist in physical education for younger children and was performed by a teacher of physical education who had undergone training. Each day a lesson concentrated on a different animal as a focus for exercise, as well as a different object and song as stimulation for activity. The participating kindergartens in the full intervention group A received these lessons daily ( $5 \mathrm{~d} /$ week) for a half an hour in the morning. At the end of each lesson the teacher filled out a participation report. The intervention was carried out in all kindergartens in the spring, between the months of March and June. 


\section{Instruments}

Anthropometric measurements and definitions

Baseline data were collected before the study began; the height and weight of each child, in light clothes, was measured by a single investigator (E.B.-Z.). BMI was calculated as the weight in kilograms divided by the square of height in metres. BMI $Z$-scores were then calculated, to take into account changes with age and sex, as provided by the Centers for Disease Control and Prevention ${ }^{(29)}$. These measurements were repeated again after 4 months, at the completion of the intervention.

\section{Daily energy intake and nutritional knowledge}

Daily energy intake was measured by using a detailed quantified FFQ designed to assess servings of highenergy-dense foods and fruits and vegetables. The FFQ has been used in previous dietary studies in Israel and its methodology has been evaluated and described ${ }^{(30,31)}$. In addition, a $24 \mathrm{~h}$ recall questionnaire was used to assess daily intake. The questionnaires were distributed to and completed by parents regarding food consumption outside the kindergarten. In the kindergarten programme, children eat a mid-morning snack that they bring from home and lunch that is provided by a catering service. Every day, after the children finished lunch, a helper would fill out a structured form that documented how much protein (meat), carbohydrates (pasta/potatoes/rice), vegetables and dessert each child ate according to a full meal, half meal, quarter meal or that the child did not eat at all. The data from the questionnaires in conjunction with the reports from the kindergarten were pooled in order to calculate daily energy intake.

The children's nutritional knowledge was assessed by a single dietitian using a questionnaire composed of seven questions regarding the food pyramid, number of fruit portions needed per day and recommended snacks and drinks.

\section{Activity, sedentary time and sleeping bours}

Parents were asked to recall the activity hours of a typical week. Activity was tabulated according to physical exercise (running, bicycle riding, etc.), sedentary activity groups (time spent watching television and using a computer) and number of hours of sleep per day.

\section{Statistical analysis}

All statistical analyses were performed using the SAS statistical software package version $9 \cdot 2$.

Categorical data were expressed as numbers and percentages and continuous variables as means and standard deviations. For comparison between all three groups at baseline the $\chi^{2}$ test for categorical variables and ANOVA for continuous variables were used.

The estimate of the effect of the intervention with 95\% confidence interval for each measure was assessed by calculating the adjusted mean differences from follow-up and baseline in the following indices: BMI $Z$-score, daily energy intake, children's knowledge level of good eating habits, physical activity time, time spent watching television/playing computer games and hours of sleep per night.

In order to take clustering into account, a mixed-effect two-level linear model was used for daily energy intake and nutritional knowledge. Each model included fixed effects: baseline measures, age, parents' education, religious status, study group and random effect of kindergarten and child. SAS MIXED procedure with LSMEANS statement was used to fit all models. All $P$ values refer to two-tailed tests; $P<0.05$ was considered significant.

\section{Results}

Table 1 demonstrates the sociodemographic characteristics at baseline of each group.

The intervention groups (A and B) and the reference group (C) had similar characteristics regarding: gender, child's country of birth, parents' country of birth, family status and number of rooms per person at home. Differences were found between groups for: age of children, parents' education and religious level. Children in the intervention groups were significantly younger than children in the reference group $(P=0 \cdot 02)$. Parents' years of education were higher in the reference group $C$ compared with the full intervention group $\mathrm{A}$ and were the lowest in the partial intervention group $\mathrm{B}(P=0 \cdot 02)$. The intervention group $\mathrm{A}$ and reference group $\mathrm{C}$ had a higher amount of religious children $(P=0 \cdot 0001)$, as they both included a state-run religious kindergarten. There were no significant differences between the leisure activities of the religious $v$. secular children (data not shown).

At baseline there was no significant difference found between groups for BMI-Z, energy intake, level of exercise and hours spent watching television or on the computer.

The reference group $\mathrm{C}$ was found to have a lower percentage of children who were obese (group A: 15.9\%, group B: $20 \cdot 9 \%$, group C: $8 \cdot 8 \%$ ). In all groups, $44-46 \%$ of children participated in exercise for $7 \mathrm{~h}$ or more per week. Similarly, in all three groups more than $50 \%$ of children spent $2 \mathrm{~h}$ or more per day watching television or playing computer games.

In all groups, $45 \cdot 1 \%$ of all children had little nutritional knowledge and $12 \cdot 7 \%$ had good nutritional knowledge. Group A had a higher percentage of children who had little nutritional knowledge (41\%) and the reference group $\mathrm{C}$ had a higher percentage of children with good nutritional knowledge (25\%). There was a significant association between level of nutritional knowledge and age $(P<0 \cdot 01)$.

On initial analysis adjusted for baseline measures, a significant reduction in daily energy intake was seen in the full intervention group A $(P=0.03)$ and a similar 
Table 1 Sociodemographic characteristics of all three study groups at baseline*: cluster-randomised controlled trial of an intervention programme to improve kindergarten children's eating and leisure habits, Israel

\begin{tabular}{|c|c|c|c|c|c|c|c|}
\hline & \multicolumn{2}{|c|}{$\begin{array}{l}\text { Group A, full intervention } \\
\qquad(n \text { 69) }\end{array}$} & \multicolumn{2}{|c|}{$\begin{array}{l}\text { Group B, partial intervention } \\
\qquad(n 67)\end{array}$} & \multicolumn{2}{|c|}{$\begin{array}{c}\text { Group C, reference } \\
(n \text { 68) }\end{array}$} & \multirow[b]{2}{*}{$P$ value } \\
\hline & $n$ & $\%$ & $n$ & $\%$ & $n$ & $\%$ & \\
\hline \multicolumn{8}{|l|}{ Age (years) } \\
\hline $4 \leq$ age $<5$ & 22 & $31 \cdot 9$ & 16 & $23 \cdot 9$ & 7 & $10 \cdot 3$ & \multirow[t]{3}{*}{0.02} \\
\hline $5 \leq$ age $<6$ & 30 & $43 \cdot 5$ & 29 & $43 \cdot 3$ & 42 & $61 \cdot 8$ & \\
\hline$\geq 6$ & 17 & $24 \cdot 6$ & 22 & $32 \cdot 8$ & 19 & $27 \cdot 9$ & \\
\hline \multicolumn{8}{|l|}{ Gender } \\
\hline Boy & 37 & $53 \cdot 6$ & 30 & $44 \cdot 8$ & 37 & $54 \cdot 4$ & \multirow[t]{2}{*}{0.46} \\
\hline Girl & 32 & $46 \cdot 4$ & 37 & $55 \cdot 2$ & 31 & $45 \cdot 6$ & \\
\hline \multicolumn{8}{|l|}{ Birthplace } \\
\hline Israel & 63 & $91 \cdot 3$ & 66 & $98 \cdot 5$ & 62 & $95 \cdot 4$ & \multirow[t]{2}{*}{$0 \cdot 15$} \\
\hline Other & 6 & $8 \cdot 7$ & 1 & $1 \cdot 5$ & 3 & $4 \cdot 6$ & \\
\hline \multicolumn{8}{|l|}{ Parents' birthplace } \\
\hline Both in Israel & 41 & $60 \cdot 3$ & 47 & $73 \cdot 4$ & 43 & $64 \cdot 2$ & \multirow[t]{3}{*}{0.61} \\
\hline One in Israel & 18 & $26 \cdot 5$ & 11 & $17 \cdot 2$ & 16 & $23 \cdot 9$ & \\
\hline Both overseas & 9 & $13 \cdot 2$ & 6 & $9 \cdot 4$ & 8 & $11 \cdot 9$ & \\
\hline \multicolumn{8}{|l|}{ Parents' education } \\
\hline Both $\geq 13$ years & 47 & $74 \cdot 6$ & 37 & $62 \cdot 7$ & 57 & $89 \cdot 1$ & \multirow{3}{*}{0.02} \\
\hline One $\geq 13$ years & 8 & $12 \cdot 7$ & 12 & $20 \cdot 3$ & 3 & $24 \cdot 7$ & \\
\hline Both $<13$ years & 8 & $12 \cdot 7$ & 10 & $17 \cdot 0$ & 4 & $6 \cdot 2$ & \\
\hline \multicolumn{8}{|l|}{ Religious level } \\
\hline Religious & 42 & $61 \cdot 8$ & 16 & $23 \cdot 9$ & 35 & $53 \cdot 0$ & \multirow[t]{2}{*}{0.0001} \\
\hline Secular & 26 & $38 \cdot 2$ & 51 & $76 \cdot 1$ & 31 & $47 \cdot 0$ & \\
\hline \multicolumn{8}{|l|}{ Family status } \\
\hline Married & 66 & $95 \cdot 6$ & 60 & $89 \cdot 5$ & 64 & $94 \cdot 1$ & \multirow[t]{2}{*}{0.34} \\
\hline Not married & 3 & $4 \cdot 4$ & 7 & $10 \cdot 5$ & 4 & $5 \cdot 9$ & \\
\hline \multicolumn{8}{|l|}{ No. of rooms per person } \\
\hline$\leq 1$ room per person & 49 & $79 \cdot 0$ & 39 & $69 \cdot 6$ & 46 & $75 \cdot 0$ & \multirow{2}{*}{0.50} \\
\hline$\geq 1$ room per person & 13 & $21 \cdot 0$ & 17 & $30 \cdot 4$ & 15 & $25 \cdot 0$ & \\
\hline
\end{tabular}

*Distributions are presented without missing values.

Table 2 Effect of the intervention after 4 months for the two intervention groups $v$. the reference group: cluster-randomised controlled trial of an intervention programme to improve kindergarten children's eating and leisure habits, Israel

\begin{tabular}{|c|c|c|c|c|c|c|c|c|}
\hline \multirow[b]{2}{*}{ Measure } & \multirow[b]{2}{*}{ Group* } & \multicolumn{2}{|c|}{ Baseline } & \multicolumn{2}{|c|}{ Follow-up } & \multicolumn{2}{|c|}{ Effect of interventiont } & \multirow[b]{2}{*}{$P$ value } \\
\hline & & Mean & SD & Mean & SD & Estimate & $95 \% \mathrm{Cl}$ & \\
\hline \multirow[t]{3}{*}{ BMI Z-score } & A & $0 \cdot 87$ & $0 \cdot 86$ & $0 \cdot 87$ & $1 \cdot 24$ & $0 \cdot 07$ & $-0.05,0.18$ & 0.25 \\
\hline & B & $0 \cdot 76$ & $1 \cdot 02$ & 0.68 & $1 \cdot 18$ & -0.01 & $-0.12,-0.11$ & 0.91 \\
\hline & C & 0.65 & $0 \cdot 71$ & 0.58 & $0 \cdot 77$ & & ference & \\
\hline \multirow[t]{3}{*}{ Daily energy intake $(\mathrm{kJ} / \mathrm{d})$} & $A$ & 5239 & 1794 & 4709 & 1717 & -583 & $-1094,-71$ & 0.03 \\
\hline & B & 5697 & 2182 & 5050 & 1808 & -489 & $-1023,45$ & 0.07 \\
\hline & C & 4948 & 1441 & 5130 & 1596 & & ference & \\
\hline \multirow[t]{3}{*}{ Nutritional knowledge (no. of correct answers) } & A & $3 \cdot 2$ & $1 \cdot 3$ & $4 \cdot 1$ & $1 \cdot 4$ & $0 \cdot 24$ & $-0 \cdot 34,0 \cdot 82$ & 0.42 \\
\hline & B & $3 \cdot 6$ & $1 \cdot 4$ & $4 \cdot 6$ & $1 \cdot 2$ & $0 \cdot 61$ & $0 \cdot 04,1 \cdot 18$ & 0.03 \\
\hline & C & $4 \cdot 5$ & $1 \cdot 4$ & $4 \cdot 4$ & $1 \cdot 3$ & & ference & \\
\hline \multirow{3}{*}{ Exercise (h/week) } & A & $8 \cdot 2$ & $5 \cdot 9$ & $8 \cdot 6$ & $4 \cdot 3$ & $-1 \cdot 20$ & $-3 \cdot 18,0 \cdot 79$ & 0.24 \\
\hline & B & $9 \cdot 2$ & $7 \cdot 7$ & $10 \cdot 3$ & $7 \cdot 0$ & 0.05 & $-1.98,2 \cdot 08$ & 0.96 \\
\hline & C & $7 \cdot 8$ & $5 \cdot 9$ & $9 \cdot 6$ & $5 \cdot 5$ & & ference & \\
\hline \multirow[t]{3}{*}{ Watching television/playing computer games $(\mathrm{h} / \mathrm{d})$} & A & $2 \cdot 3$ & $1 \cdot 0$ & $2 \cdot 2$ & $1 \cdot 0$ & -0.08 & $-0.45,0.28$ & 0.65 \\
\hline & B & $2 \cdot 1$ & $1 \cdot 0$ & $2 \cdot 2$ & $1 \cdot 1$ & 0.02 & $-0 \cdot 35,0 \cdot 39$ & 0.90 \\
\hline & C & $2 \cdot 0$ & $1 \cdot 0$ & $2 \cdot 1$ & $1 \cdot 0$ & & ference & \\
\hline \multirow[t]{3}{*}{ Sleep (h/night) } & A & $10 \cdot 1$ & 0.9 & $10 \cdot 1$ & $0 \cdot 9$ & $0 \cdot 13$ & $-0 \cdot 18,0 \cdot 44$ & $0 \cdot 40$ \\
\hline & B & $9 \cdot 9$ & 0.9 & $9 \cdot 7$ & $1 \cdot 3$ & -0.22 & $-0.53,0.10$ & $0 \cdot 17$ \\
\hline & C & $10 \cdot 2$ & 0.9 & $10 \cdot 1$ & 0.9 & $\mathrm{Re}$ & ference & \\
\hline
\end{tabular}

${ }^{*} A$, full intervention group; $B$, partial intervention group; $C$, reference group. tAdjusted for baseline measures only.

trend was demonstrated in the partial intervention group B $(P=0 \cdot 07$; see Table 2$)$.

Multivariate analysis was carried out adjusting for baseline measures, age, parents' education and religious status. Daily energy intake for group A became borderline significant $(P=0 \cdot 09)$ and the desired trend for group B was demonstrated in a similar direction $(P=0 \cdot 11$; see Table 3$)$. A significant predictor $(P<0 \cdot 01)$ of the follow-up value for daily 
Table 3 Multivariate-adjusted effect of the intervention after 4 months for the two intervention groups $v$. the reference group: clusterrandomised controlled trial of an intervention programme to improve kindergarten children's eating and leisure habits, Israel

\begin{tabular}{|c|c|c|c|c|}
\hline \multirow[b]{2}{*}{ Measure } & \multirow[b]{2}{*}{ Group* } & \multicolumn{2}{|c|}{ Multivariable-adjusted effect of interventiont } & \multirow[b]{2}{*}{$P$ value } \\
\hline & & Estimate & $95 \% \mathrm{Cl}$ & \\
\hline Daily energy intake $(\mathrm{kJ} / \mathrm{d})$ & $\begin{array}{l}A \\
B \\
C\end{array}$ & $\begin{array}{l}-566 \\
-562\end{array}$ & $\begin{array}{l}-1216,-83 \\
-1264,139\end{array}$ & $\begin{array}{l}0.09 \\
0.11\end{array}$ \\
\hline Nutritional knowledge (no. of correct answers) & $\begin{array}{l}\text { A } \\
B \\
C\end{array}$ & $\begin{array}{l}0.29 \\
0.61\end{array}$ & $\begin{array}{r}-0.54,1 \cdot 12 \\
0.23,1.46\end{array}$ & $\begin{array}{l}0.49 \\
0.15\end{array}$ \\
\hline
\end{tabular}

${ }^{*} A$, full intervention group; $B$, partial intervention group; $C$, reference group.

tAdjusted for baseline measures, age, parents' education and religious status.

energy intake was demonstrated to be the initial baseline value; children who consumed a higher amount of energy at baseline were more likely to decrease their intake.

In addition, on initial analysis with adjustment for baseline only, both intervention groups (A and B) displayed an increase in nutritional knowledge, with group B's change being significant $(P=0 \cdot 03$; Table 2$)$; upon further adjustment in multivariate analysis however, significance was reduced $(P=0 \cdot 15$; see Table 3$)$. A predictor of the children's increase in nutritional knowledge was found to be the level of parents' education, with borderline significance $(P=0 \cdot 05)$.

No changes were found in BMI $Z$-score, time spent watching television/playing computer games, exercise and sleep between the groups after the intervention.

\section{Discussion}

The present study supports the importance of the role of education for nutritional knowledge and physical activity. The aim of our study was to influence the lifestyle habits of kindergarten children using informal education to impart life skills. The significant reduction of daily energy intake, especially among children who started out with a higher daily energy intake, and improvement in nutritional knowledge support the feasibility of this type of intervention in a kindergarten setting and emphasise the necessity for the incorporation of health education into this forum from an early age.

An in-depth discussion regarding the significance of the baseline measures of these children in relation to the prevalence of overweight has been previously presented and indicated that a population-based intervention among pre-school children is required ${ }^{(3)}$. We believe that the present study complements that research and adds important information concerning the benefit of a short-term intervention focusing on lifestyle habits as a part of a prevention strategy to combat factors contributing towards obesity.

Although reduction in BMI Z-score is desired, expecting a change in this variable after a short term ( 4 months) in mostly normal-weight children is unrealistic ${ }^{(24)}$. The programme aimed to modify risk factors that contribute towards obesity as a prevention strategy, therefore the positive impact of our programme on daily energy intake and nutritional knowledge is important to note as a first step towards influencing a reduction in BMI $Z$-score as children grow. Future research should take into account long-term follow-up of prevention strategies in order to observe an impact on a complex outcome such as BMI Z-score.

The multifactorial nature of obesity and the role of environmental, social and economic factors have also been cited as reasons for not demonstrating a reduction in ageadjusted BMI despite positive changes in the behavioural outcomes under examination ${ }^{(26,32)}$. Programmes that have been effective with younger children in one population, but differed in another, suggest the need for cultural sensitivity when instituting a programme ${ }^{(33,34)}$. This may be relevant in Israel, where society is divided into different cultural groups. For example, reports on the difference in BMI among children within minority groups in Israel indicate the need for country-specific as well as cultural-specific reference curves for Israel, which may yield different results from our American counterparts ${ }^{(12,35)}$.

Similarly, other programmes that have focused on initiating behaviour change in lifestyle habits with kindergarten children have demonstrated positive trends in the behavioural outcomes studied ${ }^{(36,37)}$. However, they also did not achieve statistically significant reductions in BMI. This may be due to the fact that only a small change in BMI is expected and this would require a large sample size to be significant. As our sample size was also small (266 children), the impact of multivariate analysis weakened the findings that were adjusted for baseline measures only, even though the trend for outcomes measured was in the desired direction. The meaning and interpretation of the absolute differences in the multivariate model despite statistical insignificance should not go unnoticed, as their clinical significance and impact on a child's diet are important to recognise.

Projects targeting obesity aimed at specific behaviour patterns, including involvement of the community, have demonstrated sustained benefits with school-age children ${ }^{(38)}$. This indicates the necessity not only for longer programmes but also the involvement of parents and determinants in the child's immediate environment, as proposed by behavioural change theory ${ }^{(21,39,40)}$. 
There is a need to address the complexity of the issues surrounding obesity, especially at a young age. Other determinants that may contribute towards obesity in the younger child's environment are: the catering service provided at the kindergarten, how much a child feels in control of his/her food and lifestyle choices, peer influence in lifestyle choices, parental reinforcement of behaviour, media, and availability and accessibility to services within the surrounding community that promote healthy lifestyle habits.

In Israel, a survey on 'the status of young health and nutrition' (2004) among high-school students (11-19 years) found that the prevalence of overweight was $13-15 \%$ and of obesity was $4-9 \%$ depending on gender and ethnicity ${ }^{(41)}$. A review of medical records from a national health maintenance organisation reported overweight prevalence to be $25 \%$ and obesity prevalence to be $12 \%{ }^{(40)}$. Recent findings among students aged $8-15$ years reported $12 \%$ to be overweight and $3.6 \%$ to be obese. These students were followed into adolescence and prevalence of overweight and obesity was found to increase to $17 \%$ and $3.9 \%$, respectively ${ }^{(42)}$. Results from a study conducted in a minority community kindergarten in Israel reported the prevalence of overweight and obesity to be $27 \cdot 7 \%(26)$. These studies point towards the need for a national collaboration in the screening and monitoring of obesity. Existing data available through mother and child centres need to be centralised and school nurses could also aid in collecting data to aid policy decisions.

The strength of the present study lies in the accurate measures of height and weight of all children obtained by a single trained observer; however, she was not blinded to group assignment. A limitation encountered was that the information on dietary intake and activity was based on recall information by a proxy reporter and therefore may be prone to recall and social desirability bias. The reliability of parental responses to the $24 \mathrm{~h}$ recall and an FFQ for pre-school children has demonstrated good agreement between these measurements ${ }^{(43)}$. We similarly noted close agreement between the $24 \mathrm{~h}$ recall and FFQ, and therefore believe that our findings are reliable. On this basis, only the $24 \mathrm{~h}$ recall was used in final assessment, since both questionnaires yielded similar results. To limit information bias, there was only one person who measured height and weight with the same instruments for all kindergartens.

Finally, the study was conducted in a relatively affluent community. Differences in socio-economic status and ethnicity in relation to prevalence of overweight and the necessity of interventions aimed at nutritional knowledge and physical activity have been highlighted in previous studies from abroad and in Israel ${ }^{(26,44-47)}$. A study in Israel within a minority community incorporating a similar intervention demonstrated improvements in nutrition and physical activity knowledge and preferences, as well as improved fitness ${ }^{(26)}$. Our study builds on this research by providing data on the significant reduction of daily energy intake. Together they build evidence for the suitability of a large-scale, nationwide action within kindergartens for all children in Israel.

This project is feasible on a national level as it requires minimal time and investment by the training of kindergarten teachers and although an external physical education trainer was appointed in our intervention, the exercise programme developed is simple enough that the teachers could be trained to conduct it as well. The programme is also easy to adapt into the daily schedule of the class.

Obesity is a complex, multifactorial disease incorporating genetic, behavioural and environmental contributors and therefore it requires a multilevel intervention ${ }^{(48)}$. International efforts towards change in policy reflect the current trends in knowledge that, already at young age, obesity requires attention ${ }^{(8)}$. Intervention strategies that are multifaceted in nature are recommended to combat the obesogenic environments in which younger children find themselves in order to facilitate the development of desirable healthy behaviours ${ }^{(21,49,50)}$. This should take place within the wider context of a systems approach of tackling obesity ${ }^{(19,51)}$.

\section{Conclusion}

The present study supports the incorporation of education on healthy lifestyle habits and physical activity into the curricula of kindergartens for younger children. Further research should aim towards developing interventions with a long-term outlook to ensure the sustainability and feasibility of being instituted on a national level to bridge the gap between knowledge and practice.

\section{Acknowledgements}

Sources of funding: This research received no specific grant from any funding agency in the public, commercial or not-for-profit sectors. Conflicts of interest: There are no conflicts of interest. Ethics: This trial received institutional review board approval from Chaim Sheba Medical Center (\#3576, 2005). Authors' contributions: L.L.-G., study design, interpretation of results and writing of manuscript; E.B.-Z., study design and data collection; G.L., interpretation of results and writing of manuscript; V.B., data analysis and interpretation of results; B.R., writing of manuscript; O.P.-H., study design, interpretation of results and writing of manuscript. Acknowledgements: The authors would like to thank all participating kindergartens, parents and their children.

\section{References}

1. World Health Organization (2012) Obesity and Overweight. Fact Sheet No. 311. http://www.who.int/mediacentre/ factsheets/fs311/en/index.html (accessed June 2012). 
2. Ogden CL, Carroll MD, Kit BK et al. (2012) Prevalence of obesity and trends in body mass index among US children and adolescents, 1999-2010. JAMA 307, 483-490.

3. Pinhas-Hamiel O, Bar-Zvi E, Boyko V et al. (2009) Prevalence of overweight in kindergarten children in the centre of Israel - association with lifestyle habits. Child Care Health Dev 35, 147-152.

4. Lissau I, Overpeck MD, Ruan WJ et al. (2004) Body mass index and overweight in adolescents in 13 European countries, Israel, and the United States. Arch Pediatr Adolesc Med 158, 27-33.

5. Olds T, Maher C, Zumin S et al. (2011) Evidence that the prevalence of childhood overweight is plateauing: data from nine countries. Int J Pediatr Obes 6, 342-360.

6. Barton M (2012) Childhood obesity: a life-long health risk. Acta Pharmacol Sin 33, 189-193.

7. Berenson GS; Bogalusa Heart Study Group (2012) Health consequences of obesity. Pediatr Blood Cancer 58, $117-121$.

8. Lobstein T, Baur L \& Uauy R (2004) Obesity in children and young people: a crisis in public health. Obes Rev 5, 4-104.

9. Singh AS, Mulder C, Twisk JW et al. (2008) Tracking of childhood overweight into adulthood: a systematic review of the literature. Obes Rev 9, 474-488.

10. Speiser PW, Rudolf MCJ, Anhalt H et al. (2005) Consensus statement: childhood obesity. J Clin Endocrinol Metab 90 , 1871-1887.

11. Meydan C, Afek A, Derazne E et al. (2012) Populationbased trends in overweight and obesity: a comparative study of 2148342 Israeli male and female adolescents born 1950-1993. Pediatr Obes 8, 98-111.

12. Huerta M, Gdalevic M, Haviv J et al. (2006) Ten-year trends in obesity among Israeli schoolchildren: 1990-2000. Acta Paediatr 95, 444-449.

13. Briggs M, Safaii S \& Beall DL (2003) Position of the American Dietetic Association, Society for Nutrition Education, and American School Food Service Association Nutrition services: an essential component of comprehensive school health programs. J Am Diet Assoc 103, 505-514.

14. Haug E, Rasmussen M, Samdal O et al. (2009) Overweight in school-aged children and its relationship with demographic and lifestyle factors: results from the WHOCollaborative Health Behaviour in School-aged Children (HBSC) study. Int J Public Health 54, Suppl. 2, 167-179.

15. Maffeis C (2008) Physical activity in the prevention and treatment of childhood obesity: physio-pathologic evidence and promising experiences. Int J Pediatr Obes $\mathbf{3}$, 29-32.

16. Reilly JJ (2008) Physical activity, sedentary behaviour and energy balance in the preschool child: opportunities for early obesity prevention. Proc Nutr Soc 67, 317-325.

17. St-Onge MP, Keller KL \& Heymsfield SB (2003) Changes in childhood food consumption patterns: a cause for concern in light of increasing body weights. Am J Clin Nutr $\mathbf{7 8}$, 1068-1073.

18. Barlow SE \& Expert C (2007) Expert committee recommendations regarding the prevention, assessment, and treatment of child and adolescent overweight and obesity: summary report. Pediatrics 120, Suppl. 4, S164-S192.

19. Borys JM, Le Bodo Y, Jebb SA et al. (2012) EPODE approach for childhood obesity prevention: methods, progress and international development. Obes Rev 13, 299-315.

20. DeMattia L, Lemont L \& Meurer L (2007) Do interventions to limit sedentary behaviours change behaviour and reduce childhood obesity? A critical review of the literature. Obes $\operatorname{Rev} \mathbf{8}, 69-81$.

21. Nixon CA, Moore HJ, Douthwaite W et al. (2012) Identifying effective behavioural models and behaviour change strategies underpinning preschool- and school-based obesity prevention interventions aimed at 4-6-year-olds: a systematic review. Obes Rev 13, 106-117.

22. Lavelle HV, Mackay DF \& Pell JP (2012) Systematic review and meta-analysis of school-based interventions to reduce body mass index. J Public Health 34, 360-369.

23. Foltz JL, May AL, Belay B et al. (2012) Population-level intervention strategies and examples for obesity prevention in children. Annu Rev Nutr 32, 391-415.

24. Waters E, de Silva-Sanigorski A, Hall BJ et al. (2011) Interventions for preventing obesity in children. Cochrane Database Syst Rev issue 12, CD001871.

25. Skouteris H, Dell'Aquila D, Baur LA et al. (2012) Physical activity guidelines for preschoolers: a call for research to inform public health policy. Med J Aust 196, 174-177.

26. Nemet D, Geva D \& Eliakim A (2011) Health promotion intervention in low socioeconomic kindergarten children. J Pediatr 158, 796-801.

27. Central Bureau of Statistics (2012) Localities, their population and additional information Israel. http:// www.cbs.gov.il/reader//?MIval=\%2Fpop_in_locs\%2Fpop_ in_locs_h.html\&Name_h=\%F8\%F2\%F0\%F0\%E4 (accessed October 2013).

28. Central Bureau of Statistics (2008) Characterization and classification of geographical units by the socio-economic level of the population 2008. Publication No. 1530. http:// www.cbs.gov.il/publications13/1530/pdf/map01_01_e.pdf (accessed October 2013).

29. US National Center for Health Statistics (2006) CDC growth charts. http://www.cdc.gov/nchs/about/major/ nhanes/growthcharts/charts.htm (accessed November 2006).

30. Willett WC, Sampson L, Stampfer MJ et al. (1985) Reproducibility and validity of a semiquantitative food frequency questionnaire. Am J Epidemiol 122, 51-65.

31. Lubin F, Chetrit A, Lusky A et al. (1998) Methodology of a two-step quantified nutritional questionnaire and its effect on results. Nutr Cancer 30, 78-82.

32. Reilly JJ, Kelly L, Montgomery C et al. (2006) Physical activity to prevent obesity in young children: cluster randomised controlled trial. BMJ 333, 1041.

33. Fitzgibbon ML, Stolley MR, Schiffer L et al. (2005) Two-year follow-up results for Hip-Hop to Health Jr.: a randomized controlled trial for overweight prevention in preschool minority children. J Pediatr 146, 618-625.

34. Fitzgibbon ML, Stolley MR, Schiffer L et al. (2006) Hip-Hop to Health Jr. for Latino preschool children. Obesity (Silver Spring) 14, 1616-1625.

35. Ram E, Marcus O, Joubran S et al. (2013) Prevalence of obesity among Arab school children in Nazareth, Israel: comparison with national (Jewish) and international data. Pediatr Obes 8, 428-438.

36. Bayer O, von Kries R, Strauss A et al. (2009) Short- and midterm effects of a setting based prevention program to reduce obesity risk factors in children: a cluster-randomized trial. Clin Nutr 28, 122-128.

37. Dennison BA, Russo TJ, Burdick PA et al. (2004) An intervention to reduce television viewing by preschool children. Arch Pediatr Adolesc Med 158, 170-176.

38. Taylor RW, McAuley KA, Barbezat W et al. (2008) Two-year follow-up of an obesity prevention initiative in children: the APPLE project. Am J Clin Nutr 88, 1371-1377.

39. Boneberger A, Von Kries R, Milde-Busch A et al. (2009) Association between peer relationship problems and childhood overweight/obesity. Acta Paediatr 98, 1950-1955.

40. Skouteris H, McCabe M, Swinburn B et al. (2011) Parental influence and obesity prevention in pre-schoolers: a systematic review of interventions. Obes Rev 12, 315-328.

41. Kaluski DN, Demem Mazengia G, Shimony T et al. (2009) Prevalence and determinants of physical activity and 
lifestyle in relation to obesity among schoolchildren in Israel. Public Health Nutr 12, 774-782.

42. Meyerovitch J, Goldman RD, Avner-Cohen $\mathrm{H}$ et al. (2007) Primary care screening for childhood obesity: a population-based analysis. Isr Med Assoc J 9, 782-786.

43. Parrish LA, Marshall JA, Krebs NF et al. (2003) Validation of a food frequency questionnaire in preschool children. Epidemiology 14, 213-217.

44. Bambra CL, Hillier FC, Moore HJ et al. (2012) Tackling inequalities in obesity: a protocol for a systematic review of the effectiveness of public health interventions at reducing socioeconomic inequalities in obesity amongst children. Syst Rev 1, 16.

45. Fitzgibbon ML, Stolley MR, Schiffer LA et al. (2011) Hip-Hop to Health Jr. Obesity Prevention Effectiveness Trial: postintervention results. Obesity (Silver Spring) 19, 994-1003.
46. Jouret B, Ahluwalia N, Dupuy M et al. (2009) Prevention of overweight in preschool children: results of kindergartenbased interventions. Int J Obes (Lond) 33, 1075-1083.

47. Khader Y, Irshaidat O, Khasawneh M et al. (2009) Overweight and obesity among school children in Jordan: prevalence and associated factors. Matern Child Health J 13, 424-431.

48. Karnik S \& Kanekar A (2012) Childhood obesity: a global public health crisis. Int J Prev Med 31, 1-7.

49. Kopelman P, Jebb SA \& Butland B (2007) Executive summary: foresight 'Tackling Obesities: Future Choices' project. Obes $\operatorname{Rev} \mathbf{8}$, vi-ix.

50. Summerbell CD, Moore HJ, Vogele C et al. (2012) Evidence-based recommendations for the development of obesity prevention programs targeted at preschool children. Obes Rev 13, 129-132.

51. Gortmaker SL, Swinburn BA, Levy D et al. (2011) Changing the future of obesity: science, policy, and action. Lancet 378, 838-847. 